\title{
ENGENHEIRAS NO CEFET-PR?
}

Resumo

\author{
Lindamir Salete Casagrande ${ }^{1}$ \\ Juliana Schwartz ${ }^{2}$ \\ Marilia Gomes de Carvalho ${ }^{3}$ \\ Sonia Ana Leszczynski ${ }^{4}$
}

A participação da mulher no mundo acadêmico tem aumentado nas últimas décadas, porém, estudos apontam que em algumas áreas, como as ciências exatas e particularmente as engenharias, embora o número de mulheres nesses cursos seja crescente, elas ainda são minoria no Brasil. A pesquisa ora apresentada tem por objetivo verificar se os Cursos de Engenharia do Centro Federal de Educação Tecnológica do Paraná - CEFET-PR acompanham a tendência nacional de aumento da participação feminina no seu quadro discente. A escolha do CEFET-PR deu-se por esta ser uma instituição que tem tradição, em Curitiba-Paraná, em cursos na área tecnológica e que desde 1978 oferece à comunidade cursos Industriais de Engenharia. Para a realização deste estudo, será feito o levantamento por sexo do número de alunos calouros e formandos nas Engenharias.

Palavras-Chave: Engenharia, Mulheres, CEFET-PR, Participação Feminina

\section{INTRODUÇÃO}

O interesse e a participação das mulheres nas ciências não de deu apenas a partir do século XX como se pode pensar. Nos séculos XVII e XVIII, assim como seus colegas masculinos, as mulheres estudavam várias ciências como astronomia, física, matemática, química, filosofia, dentre outras. As universidades italianas, no século XIII, foram grandes receptoras das mulheres que conseguiram ter acesso à universidade, possibilitando a elas além de estudar também lecionar em disciplinas como física e matemática. ${ }^{5}$

Segundo Londa Schienbinger ${ }^{6}$, a formalização da ciência no século $\mathrm{XIX}$, que tornou o estudo nas universidades obrigatório para ter uma carreira científica, fez com que as mulheres fossem afastadas das universidades, pois esta passou a ser uma área considerada masculina. Porém, algumas mulheres usaram subterfúgios para conseguirem maneiras de burlar esta proibição. Dentre eles pode-se citar que algumas forjavam identidades masculinas bem como passavam a ser assistente de familiares homens, como pais ou maridos em seus estudos científicos, e desta forma tinham a possibilidade de se dedicarem às ciências.

1 Mestra em Tecnologia - PPGTE do Centro Federal de Educação Tecnológica do Paraná CEFET-PR, licenciada em matemática, especialista em Fundamentos da Matemática, pesquisadora do Grupo de Estudos e Pesquisas sobre Relações de Gênero e Tecnologia GeTec (www.ppgte.cefetpr.br/genero) e professora do CEFET-PR.

2 Mestra em Tecnologia pelo PPGTE /CEFET-PR, engenheira da computação, especialista em teleinformática e redes de computadores e pesquisadora do GeTec (www.ppgte.cefetpr.br/genero).

3 Doutora em Antropologia Social, professora do PPGTE /CEFET-PR, coordenadora e pesquisadora do GeTec (www.ppgte.cefetpr.br/genero).

4 Doutora em Educação, professora do PPGTE / CEFET-PR e Assessora de Ações Acadêmicas e Projetos Sociais do CEFET-PR.

5 SCHIEBINGER, 2001,p. 60,61.

6 SCHIENBINGER, 2001, p.64. 
O movimento das mulheres nas décadas de 1870 e 1880 conseguiu garantir o acesso feminino às universidades, podendo assim escolher sua carreira profissional. Desde então, a participação feminina nas ciências tem crescido em todos os países. Porém, Fanny Tabak ${ }^{7}$ aponta que elas se concentram em áreas consideradas femininas, como educação e saúde e, apesar de sua participação nas áreas exatas estar aumentando, em engenharia, por exemplo, elas continuam sendo minoria no corpo docente e discente.

Sendo o Centro Federal de Educação Tecnológica do Paraná (CEFET-PR) uma instituição com tradição nos cursos da área tecnológica, torna-se relevante verificar se os Cursos de Engenharia do CEFET-PR acompanham a tendência nacional de aúmento da participação feminina em seu quadro discente.

Para a realização deste estudo, será feito o levantamento por sexo do número de alunos calouros e formandos nas Engenharias, de 1988 a 2003, com intuito de verificar a evolução da participação feminina nesses cursos

\section{A Instituição CEFET-PR e os Cursos de Engenharia}

O Centro Federal de Educação Tecnológica do Paraná, CEFET-PR, "é uma autarquia de regime especial, vinculada ao Ministério da Educação"в. Atualmente, o CEFET-PR conta com 06 Unidades de Ensino, em Curitiba, Pato Branco, Dois Vizinhos, Campo Mourão, Cornélio Procópio, Medianeira e Ponta Grossa sendo que a sede do sistema CEFET-PR encontra-se em Curitiba.

A instituição foi fundada em 1909 como Escola de Aprendizes e Artífices do Paraná. Em 1978, foi transformada em Centro Federal de Educação Tecnológica do Paraná, passando a ter além do ensino técnico, o ensino superior. Atualmente, o CEFET-PR oferece ensino de segundo grau, superior, pós-graduação (especialização, mestrado e doutorado), além de cursos de extensão e aperfeiçoamento.

Desde 1978, o CEFET-PR passa a oferecer para a comunidade também cursos na área de engenharia. Atualmente são ofertados os cursos de Engenharia Industrial Elétrica (Eletrotécnica e Eletrônica/Telecomunicações), Engenharia Industrial Mecânica, Engenharia de Produção Civil e Engenharia Agronômica, este último na unidade de Pato Branco.

Os cursos têm duração de 10 semestres, sendo que após o primeiro semestre os alunos podem adiantar o currículo e se formar em menos tempo do que o estipulado. $O$ ingresso nos cursos acontece através de concurso vestibular duas vezes por ano.

\section{Mulheres na Engenharia}

Neste item será analisada a participação feminina nas engenharias,

TABAK, 2002, p. xxx

CEFET-PR, Apresentação, disponível em www.cefetpr.br 
área tida como masculina.

Que as mulheres ingressam nos cursos de Engenharia não é mais novidade. Porém a menor participação feminina em relação à masculina, ainda é visível. Através dos dados do censo de 2002, realizado pelo CNPq (Conselho Nacional de Desenvolvimento Científico e Tecnológico), o número de mulheres cursando mestrado e doutorado na área das engenharias é de $23,7 \%$ (TABELA 1), número pequeno se comparado à área de ciências humanas, onde elas são $59 \%$ das bolsistas.

TABELA 1 - Censo de 2002

\begin{tabular}{l|c|l|l|l|l|l|l|l|l}
\hline \multirow{2}{*}{ Grande área } & \multirow{2}{*}{$\begin{array}{c}\text { Total } \\
\text { Geral }\end{array}$} & \multicolumn{3}{|c|}{ Mestrado } & \multicolumn{3}{c|}{ Doutorado } & \multicolumn{2}{c}{ Porcentagem } \\
\cline { 3 - 10 } & & Masc. & Fem. & $\begin{array}{c}\text { Não } \\
\text { inf. }\end{array}$ & Masc. & Fem. & $\begin{array}{c}\text { Não } \\
\text { inf. }\end{array}$ & $\begin{array}{c}\text { Masc. } \\
\%\end{array}$ & $\begin{array}{l}\text { Fem } \\
\%\end{array}$ \\
\hline Ciências Agrárias & 7.150 & 1.238 & 766 & 0 & 3.626 & 1.520 & 0 & 68 & 32 \\
\hline Ciências Biológicas & 7.624 & 685 & 1.005 & 0 & 2.954 & 2.980 & 0 & 47,7 & 52,3 \\
\hline Ciências Exatas e da Terra & 7.511 & 773 & 508 & 0 & 4.454 & 1.774 & 2 & 69,6 & 30,4 \\
\hline Ciências Humanas & 9.133 & 1.269 & 2.360 & 0 & 2.481 & 3.022 & 1 & 41 & 59 \\
\hline Ciências Sociais Aplicadas & 4.875 & 956 & 1.065 & 0 & 1.698 & 1.156 & 0 & 54,4 & 45,6 \\
\hline Ciências da Saúde & 8.743 & 814 & 1.971 & 0 & 2.967 & 2.990 & 1 & 43,2 & 56,8 \\
\hline Engenharias e Ciências da & 8.439 & 1.616 & 706 & 0 & 4.820 & 1.297 & 0 & 76,2 & 23,8 \\
computação & & & & & & & & & \\
\hline Lingüística, Letras e Artes & 2.483 & 245 & 618 & 0 & 555 & 1.065 & 0 & 32,2 & 67,8 \\
\hline Totais & 55.958 & 7.596 & $\mathbf{8 . 9 9 9}$ & $\mathbf{0}$ & $\mathbf{2 3 . 5 5 5}$ & $\mathbf{1 5 . 8 0 4}$ & $\mathbf{4}$ & $\mathbf{5 5 , 7}$ & $\mathbf{4 4 , 3}$ \\
\hline
\end{tabular}

FONTE - CENSO 2002 DO CNPq

Em março de 2004, o Instituto Nacional de Estudos e Pesquisas Educacionais Anísio Teixeira ${ }^{10}$ (INEP/MEC) apresentou o Censo da Educação Superior (TABELA 2). Neste censo, é possível verificar que o número de engenheiras cresceu 67,8\% em 12 anos. Em 1991, haviam 25,5 mil alunas matriculadas em cursos de engenharia no Brasil, este número subiu para 42,8 mil em 2002. Assim, as mulheres passaram a representar $20,3 \%$ dos estudantes de engenharia.

9 ver www.cnpq.br

10 INEP, 2004. Notícia disponível em http://www.inep.gov.br/imprensa/noticias/censo/superior/news04_03.htm 
TABELA 2 - Censo da Educação Superior de 2002

\begin{tabular}{|c|c|c|c|}
\hline & & 1991 & 2002 \\
\hline ENGENHARIAS & $\begin{array}{l}\text { Total } \\
\text { Mulheres } \\
\% \text { de mulheres }\end{array}$ & $\begin{array}{l}146.806 \\
25.503 \\
17,4\end{array}$ & $\begin{array}{l}211.009 \\
42.802 \\
20,3\end{array}$ \\
\hline ARQUITETURA & $\begin{array}{l}\text { Total } \\
\text { Mulheres } \\
\% \text { de mulheres }\end{array}$ & $\begin{array}{l}21.881 \\
12.986 \\
59,3 \\
\end{array}$ & $\begin{array}{l}44.506 \\
28.245 \\
63,5 \\
\end{array}$ \\
\hline FISIOTERAPIA & $\begin{array}{l}\text { Total } \\
\text { Mulheres } \\
\% \text { de mulheres }\end{array}$ & $\begin{array}{l}11.379 \\
8.301 \\
73\end{array}$ & $\begin{array}{l}78.099 \\
59.079 \\
75,6\end{array}$ \\
\hline ODONTOLOGIA & $\begin{array}{l}\text { Total } \\
\text { Mulheres } \\
\% \text { de mulheres }\end{array}$ & $\begin{array}{l}30.575 \\
18.009 \\
58,9\end{array}$ & $\begin{array}{l}47.716 \\
29.741 \\
62,3\end{array}$ \\
\hline DIREITO & $\begin{array}{l}\text { Total } \\
\text { Mulheres } \\
\% \text { de mulheres }\end{array}$ & $\begin{array}{l}159.390 \\
70.015 \\
43,9\end{array}$ & $\begin{array}{l}463.135 \\
226.307 \\
48,9\end{array}$ \\
\hline ADMINISTRAÇÃO & $\begin{array}{l}\text { Total } \\
\text { Mulheres } \\
\% \text { de mulheres }\end{array}$ & $\begin{array}{l}177.838 \\
73.157 \\
41,1 \\
\end{array}$ & $\begin{array}{l}454.438 \\
215.926 \\
47,5 \\
\end{array}$ \\
\hline PEDAGOGIA & $\begin{array}{l}\text { Total } \\
\text { Mulheres } \\
\% \text { de mulheres }\end{array}$ & $\begin{array}{l}116.253 \\
106.023 \\
91,2 \\
\end{array}$ & $\begin{array}{l}240.368 \\
221.998 \\
92,4 \\
\end{array}$ \\
\hline FÍSICA & $\begin{array}{l}\text { Total } \\
\text { Mulheres } \\
\% \text { de mulheres }\end{array}$ & $\begin{array}{l}7.950 \\
1.441 \\
18,1 \\
\end{array}$ & $\begin{array}{l}17.866 \\
3.769 \\
21,1\end{array}$ \\
\hline QUÍMICA & $\begin{array}{l}\text { Total } \\
\text { Mulheres } \\
\% \text { de mulheres }\end{array}$ & $\begin{array}{l}8.856 \\
3.900 \\
44,0 \\
\end{array}$ & $\begin{array}{l}26.268 \\
13.035 \\
49,6\end{array}$ \\
\hline MATEMÁTICA & $\begin{array}{l}\text { Total } \\
\text { Mulheres } \\
\% \text { de mulheres }\end{array}$ & $\begin{array}{l}21.955 \\
9.422 \\
42,9\end{array}$ & $\begin{array}{l}66.256 \\
33.245 \\
50,2\end{array}$ \\
\hline LETRAS & $\begin{array}{l}\text { Total } \\
\text { Mulheres } \\
\% \text { de mulheres }\end{array}$ & $\begin{array}{l}92.891 \\
75.597 \\
81.6\end{array}$ & $\begin{array}{l}158.562 \\
130.813 \\
82.5\end{array}$ \\
\hline $\begin{array}{l}\text { TOTAL GERAL } \\
\text { (todos os cursos) }\end{array}$ & $\begin{array}{l}\text { Total } \\
\text { Mulheres } \\
\% \text { de mulheres }\end{array}$ & $\begin{array}{l}1.565 .056 \\
833.949 \\
53,3\end{array}$ & $\begin{array}{l}3.476 .194 \\
1.964 .649 \\
56,5\end{array}$ \\
\hline
\end{tabular}

Fonte: Inep/MEC

Ao falar das mulheres nas engenharias, Karla Saraiva aponta que "se desde cedo aprendemos que somos pouco dotadas para o raciocínio abstrato, para o trato com o mundo da produção, para liderança e para tomadas de decisão, optar por um curso de engenharia para nós significa aceitar o desafio de ultrapassar nossas 'limitações'." "11 Segundo a autora, o fato do título de engenheira não existir no Brasil até 1988, é uma forma de negar a existência das mulheres engenheiras.

11 SARAIVA, 2003, p. 6. 
A não aceitação da entrada de mulheres em curso de engenharia, ocupando o espaço masculino, fez com que em 6 de dezembro de 1989 um estudante assassinasse quatorze mulheres, todas estudantes de engenharia. $\mathrm{O}$ massacre ${ }^{12}$, conhecido como gendercide (massacre de gênero) ocorreu em uma sala de aula da Ėcole Polytechnique da Universidade de Montreal. Como sinal de apoio às colegas assassinadas, foi criado o movimento White Ribbon, que hoje se espalhou pelo mundo todo, onde os homens usam uma fita branca simbolizando o repúdio a violência contra a mulher.

Em contraponto, em agosto deste ano, o Massachusetts Institute of Techonology (MIT) elegeu a primeira presidente mulher. Conhecida por ser uma instituição tradicionalmente masculina, Susan Hockfield será a $16^{\text {a }}$ presidente $^{13}$, o que representa uma mudança significativa no modo de ver a participação feminina no MIT.

Pode-se perceber que não é tarefa das mais simples cursar engenharia e isso não ocorre somente no Brasil, tendo em vista o ocorrido no Canadá. Entretanto mesmo com dificuldades algumas conseguem se destacar neste universo masculino como Susan.

\section{A evolução da participação feminina nos cursos de Engenharia do CEFET-PR}

Neste item será analisada a participação feminina nos cursos de engenharia do CEFET-PR. Os dados apresentados nos quadros 1, 2, 3 e 4 foram obtidos junto aos arquivos da Divisão de Orçamento e Estatística do CEFET-PR. Serão apresentados em intervalos de 5 anos e separados por curso e por sexo.

A presença feminina no CEFET-PR ocorre tanto no quadro docente quanto discente, entretanto, neste estudo serão apresentados apenas os números referentes ao quadro discente.

A evolução do número de mulheres matriculadas nos curso de engenharia no CEFET-PR está representada no QUADRO 1. Observa-se que o número de mulheres é bem menor do que o número de homens em todos os cursos. Percebe-se que houve um pequeno acréscimo do número de mulheres matriculadas nos diversos cursos cujo ápice foi no ano de 1998, ano em que se chegou a $18 \%$ do total de alunos. Este acréscimo pode ter sido reflexo dos acontecimentos da década de 1990 no qual houve maior abertura para a participação feminina em todas as áreas do conhecimento. No ano de 2003 houve uma queda do número de alunas matriculadas nos cursos de engenharia do CEFET-PR o que pode ter sido causado pela criação dos cursos de Superiores de Tecnologia na referida instituição, porém para uma afirmação mais precisa há necessidade de se realizar pesquisa com este intuito.

12 Mais informações disponível em www.gendercide.org/case_montreal.html

13 ANDERSON, 2004. Notícia completa em http://www.biomedcentral.com/news/20040831/01. 


\begin{tabular}{|c|c|c|c|c|c|c|c|c|c|c|c|c|}
\hline & \multicolumn{3}{|c|}{1988} & \multicolumn{3}{|c|}{1993} & \multicolumn{3}{|c|}{1998} & \multicolumn{3}{|c|}{2003} \\
\hline & Masc. & Fem. & Tot. & Masc. & Fem. & Tot. & Masc. & Fem. & Tot. & Masc. & Fem. & Tot. \\
\hline $\begin{array}{l}\text { Engenharia } \\
\text { Industrial } \\
\text { Eletrônica }\end{array}$ & 859 & 52 & 911 & 835 & 65 & 900 & 717 & 114 & 831 & 837 & 67 & 904 \\
\hline $\begin{array}{l}\text { Engenharia } \\
\text { Industrial } \\
\text { Eletrotécnica }\end{array}$ & 788 & 69 & 857 & 845 & 65 & 910 & 701 & 134 & 835 & 797 & 95 & 892 \\
\hline $\begin{array}{l}\text { Engenharia } \\
\text { Industrial } \\
\text { Mecânica }\end{array}$ & - & - & - & 247 & 4 & 251 & 758 & 102 & 860 & 872 & 69 & 941 \\
\hline $\begin{array}{l}\text { Engenharia da } \\
\text { Produção Civil }\end{array}$ & - & - & - & - & - & - & 166 & 164 & 330 & 493 & 287 & 780 \\
\hline $\begin{array}{l}\text { Tecnologia em } \\
\text { Const. Civil }\end{array}$ & 142 & 46 & 188 & 137 & 72 & 209 & 12 & 4 & 16 & - & - & - \\
\hline Total & 1789 & 167 & 1956 & 2064 & 206 & 2270 & 2354 & 518 & 2872 & 2999 & 518 & 3517 \\
\hline
\end{tabular}

Fonte: Divisão de Orçamento e Estatística do CEFET-PR

Percebe-se ainda que a maior participação feminina ocorre no curso de Tecnologia em Construção Civil que posteriormente transformou-se em Engenharia da Produção Civil onde a porcentagem de mulheres matriculadas em 2003 foi de $37 \%$. Por outro lado, a menor participação de mulheres se encontra em Engenharia Industrial Mecânica e Engenharia Industrial Eletrônica onde as mulheres representam apenas $7 \%$ do total de alunos. Esses dados podem ser melhor visualizados no QUADRO 2 que apresenta a porcentagem de mulheres matriculadas em cada curso e ano selecionados para análise.

QUADRO 2 - PORCENTAGEM DE MULHERES MATRICULADAS POR CURSO

\begin{tabular}{|c|c|c|c|c|}
\hline & 1988 & 1993 & 1998 & 2003 \\
\hline Engenharia Industrial Eletrônica & $6 \%$ & $7 \%$ & $14 \%$ & $7 \%$ \\
\hline Engenharia Industrial Eletrotécnica & $8 \%$ & $7 \%$ & $16 \%$ & $11 \%$ \\
\hline Engenharia Industrial Mecânica & - & $2 \%$ & $12 \%$ & $7 \%$ \\
\hline Engenharia da Produção Civil & - & - & $49 \%$ & $37 \%$ \\
\hline Tecnologia em Construção Civil & $24 \%$ & $34 \%$ & $25 \%$ & - \\
\hline Total & $9 \%$ & $9 \%$ & $18 \%$ & $15 \%$ \\
\hline
\end{tabular}

Fonte: Divisão de Orçamento e Estatística do CEFET-PR

O QUADRO 3 apresenta o número de alunos e alunas concluintes nos mesmos cursos e períodos. Também aqui se encontra um número de mulheres significativamente menor do que o número de homens em quase todos os cursos e períodos. A exceção dá-se no ano de 1988, em que a porcentagem de formadas era de $13 \%$ devido ao grande percentual de mulheres concluintes 
em Tecnologia em Construção Civil (75\%). Após queda nos anos consecutivos, o número de mulheres concluintes voltou a aumentar no ano de 2003 quando atingiu $10 \%$ do total de alunos, porém continua representando uma pequena parcela do total de formados.

QUADRO 3 - ALUNOS FORMANDOS POR SEXO E POR CURSO

\begin{tabular}{|c|c|c|c|c|c|c|c|c|c|c|c|c|}
\hline & \multicolumn{3}{|c|}{1988} & \multicolumn{3}{|c|}{1993} & \multicolumn{3}{|c|}{1998} & \multicolumn{3}{|c|}{2003} \\
\hline & Masc. & Fem. & Tot. & Masc. & Fem. & Tol. & Masc. & Fem. & Tot. & Masc. & Fem. & Tot. \\
\hline $\begin{array}{l}\text { Engenharia } \\
\text { Industrial } \\
\text { Eletrônica }\end{array}$ & 40 & 5 & 45 & 48 & 5 & 53 & 63 & 2 & 65 & 51 & 3 & 54 \\
\hline $\begin{array}{l}\text { Engenharia } \\
\text { Industrial } \\
\text { Eletrotécnica }\end{array}$ & 45 & 2 & 47 & 40 & 2 & 42 & 50 & 4 & 54 & 49 & 7 & 56 \\
\hline $\begin{array}{l}\text { Engenharia } \\
\text { Industrial } \\
\text { Mecânica }\end{array}$ & . & - & - & - & - & - & 43 & 0 & 43 & 56 & 6 & 62 \\
\hline $\begin{array}{l}\text { Engenharia da } \\
\text { Produção Civil }\end{array}$ & - & - & - & - & - & - & - & - & - & 33 & 25 & 58 \\
\hline $\begin{array}{l}\text { Tecnologia em } \\
\text { Const. Civil }\end{array}$ & 2 & 6 & 8 & 6 & 1 & 7 & 7 & 1 & 8 & - & - & - \\
\hline Total & 87 & 13 & 100 & 94 & 8 & 102 & 163 & 7 & 170 & 156 & 16 & 172 \\
\hline
\end{tabular}

Fonte: Divisão de Orçamento e estatística do CEFET-PR

Também com relação aos formandos o curso que apresenta maior participação feminina é o de Tecnologia em Construção Civil que posteriormente se transformou em Engenharia da Produção Civil onde a porcentagem de mulheres formadas é de 43\% em 2003.

QUADRO 4 - PORCENTAGEM DE MULHERES FORMADAS POR CURSO

\begin{tabular}{l|c|c|c|c}
\cline { 2 - 5 } & $\mathbf{1 9 8 8}$ & $\mathbf{1 9 9 3}$ & $\mathbf{1 9 9 8}$ & $\mathbf{2 0 0 3}$ \\
\hline Engenharia Industrial Eletrônica & $11 \%$ & $9 \%$ & $3 \%$ & $6 \%$ \\
\hline Engenharia Industrial Eletrotécnica & $4 \%$ & $5 \%$ & $7 \%$ & $13 \%$ \\
\hline Engenharia Industrial Mecânica & - & - & $0 \%$ & $10 \%$ \\
\hline Engenharia da Produção & - & - & - & $43 \%$ \\
\hline Tecnologia em Construção Civil & $75 \%$ & $14 \%$ & $13 \%$ & 0 \\
\hline \multicolumn{1}{r|}{ Total } & $13 \%$ & $\mathbf{8} \%$ & $\mathbf{4} \%$ & $10 \%$ \\
\hline
\end{tabular}

Fonte: Divisão de Orçamento e estatística do CEFET-PR

Entretanto o curso com a menor participação feminina foi o Curso de Engenharia Industrial Eletrônica onde a porcentagem de mulheres formadas ficou em $6 \%$ em 2003. 


\section{Considerações finais}

Com o desenvolvimento deste estudo pôde-se observar que os cursos de Engenharia do CEFET-PR apresentam um crescimento do número de mulheres em seu quadro discente o que vem de encontro com a tendência nacional de incremento da participação feminina na área de ciências exatas e mais especificamente nas Engenharias.

Os núneros relativos à participação das mulheres nas engenharias do CEFET-PR ainda são baixos, porém apresenta-se em uma crescente o que pode indicar que futuramente pode-se ter reduzida a diferença entre a participação de homens e mulheres nestes cursos.

O estudo ora apresentado encontra-se ainda em desenvolvimento e em sua segunda etapa prevê a análise das causas que trazem os alunos e alunas ao CEFET-PR.

E assim respondendo a pergunta título deste estudo pode-se dizer que existem engenheiras no CEFET-PR. Elas são minoria, mas estão lá marcando seu espaço neste universo masculino.

\section{Referências bibliiográficas}

ANDERSON, Maria. "First woman to head MIT". The Scientist, 31 de agosto de 2004. Disponivel em http://www.biomedcentral.com/news/20040831/01

INEP, "Aumenta participação feminina em cursos de engenharia" . 08 de março de 2004. Disponivel em http://www.inep.gov.br/imprensa/noticias/censo/superior/news04_03.htm

SARAIVA, Karla Schuck. "Fabricando Identidades Femininas Em Escolas De Engenharia". In: II Seminário Internacional Educação Intercultural, Gênero e Movimentos Sociais, Florianópolis. Disponivel em

http://www.rizoma.ufsc.br/semint/trabalhos/Karla\%20S.Saraiva_UNISINOS.doc

SCHIENBINGER, Londa. O feminismo mudou a ciência? São Paulo: EDUSC, 2001.

TABAK, Fanny. O laboratório de Pandora: estudos sobre a ciência no feminino. Rio de Janeiro: Garamond, 2002. 